\title{
Editorial
}

\section{Nanosized Photocatalytic Materials 2013}

\author{
Jiaguo Yu, ${ }^{1}$ Christos Trapalis, ${ }^{2}$ Huogen Yu, ${ }^{3}$ Wenhong Fan, ${ }^{4}$ and Hong Liu ${ }^{5}$ \\ ${ }^{1}$ State Key Laboratory of Advanced Technology for Material Synthesis and Processing, Wuhan University of Technology, \\ Luoshi Road No. 122, Wuhan 430070, China \\ ${ }^{2}$ Institute of Materials Science, National Centre for Scientific Research "Demokritos", Ag. Paraskevi, Attikis, Greece \\ ${ }^{3}$ Department of Chemistry, School of Science, Wuhan University of Technology, Luoshi Road No. 122, Wuhan 430070, China \\ ${ }^{4}$ School of Chemistry and Environment, Beijing University of Aeronautics and Astronautics, Beijing 100191, China \\ ${ }^{5}$ Chongqing Institute of Green and Intelligent Technology, Chinese Academy of Sciences, Chongqing 401122, China
}

Correspondence should be addressed to Jiaguo Yu; jiaguoyu@yahoo.com

Received 23 February 2014; Accepted 23 February 2014; Published 23 March 2014

Copyright (C) 2014 Jiaguo Yu et al. This is an open access article distributed under the Creative Commons Attribution License, which permits unrestricted use, distribution, and reproduction in any medium, provided the original work is properly cited.

Semiconductor photocatalytic materials have attracted considerable attention in the fields of solar energy conversion and environmental protection. However, their photocatalytic performance should be further enhanced from the viewpoints of practical applications and commercial benefits. Nanosized photocatalytic materials because of their novel properties have created more opportunities in extending their applications in various fields such as water and air purifications, hydrogen generation, $\mathrm{CO}_{2}$ reduction, and dyesensitized solar cells. A rapid growth of these applications indicates a need for the assessment of potential risk of nanomaterials to environment and organisms.

This special issue contains 11 papers, mainly related to preparation, characterization, and environmental purification of nanosized photocatalytic materials. Among them 4 papers are about fabrication of $\mathrm{TiO}_{2}$, and 6 papers deal with fabrication of non- $\mathrm{TiO}_{2}$ photocatalytic materials including $\mathrm{CeVO}_{4}, \mathrm{ZrFe}_{2} \mathrm{O}_{5}, \mathrm{AgBr} / \mathrm{Ag}_{3} \mathrm{PO}_{4}, \mathrm{Bi}_{2} \mathrm{O}_{3}, \mathrm{Bi}_{2} \mathrm{MoO}_{6}$, and $\mathrm{ZnO}$. Furthermore, there are 2 review papers published in this special issue. A brief summary of all 11 accepted papers is provided as follows.

In " $3 D$ CFD simulations of MOCVD synthesis system of titanium dioxide nanoparticles," the authors describe the 3dimensional (3D) computational fluid dynamics simulation study of metal organic chemical vapor deposition (MOCVD) producing photocatalytic $\mathrm{TiO}_{2}$ nanoparticles, which will provide better understanding of the MOCVD synthesis system especially for deposition process of $\mathrm{TiO}_{2}$ nanoparticles as well as fluid dynamics inside the reactor.
The paper " $\mathrm{TiO}_{2}$ deposition on AZ31 magnesium alloy using plasma electrolytic oxidation" reports fabrication of oxide films containing $\mathrm{TiO}_{2}$ nanoparticles on AZ31 magnesium alloy using plasma electrolytic oxidation (PEO) in phosphate electrolyte with the addition of $\mathrm{TiO}_{2}$ nanoparticles. The corrosion resistance of the PEO treated samples was evaluated with electrochemical impedance spectroscopy (EIS) and DC polarization tests in $3.5 \mathrm{wt} . \% \mathrm{NaCl}$.

The paper " $\mathrm{TiO}_{2}$-based photocatalytic process for purification of polluted water: Bridging fundamentals to applications" reviews the fundamentals that govern the actual water purification process, including the fabrication of engineered $\mathrm{TiO}_{2}$ based photocatalysts, process optimization, reactor design, and economic consideration. The state-of-the-art of photocatalyst preparation, strategies for process optimization, and reactor design determines the enhanced separation of photoexcited electron-hole (e-h) pairs on the $\mathrm{TiO}_{2}$ surface.

The paper "Synthesis and characterization of $\mathrm{CeVO}_{4}$ by microwave radiation method and its photocatalytic activity" describes a microwave radiation method for synthesizing nanostructured $\mathrm{CeVO}_{4}$. The result indicated that the $\mathrm{pH}$ of the precursor solutions was the key factor to control the morphologies of $\mathrm{CeVO}_{4}$ : nanoparticles, nanorods, and microflowers.

The paper "Characterization of newly synthesized $\mathrm{ZrFe}_{2} \mathrm{O}_{5}$ nanomaterial and investigations of its tremendous photocatalytic properties under visible light irradiation" reported the photocatalytic performance of $\mathrm{ZrFe}_{2} \mathrm{O}_{5}$ nanoparticles by measuring the degradation rate of toluidine blue $\mathrm{O}(\mathrm{TBO})$ 
dye in aqueous solution under visible light irradiation. The degradation efficiency was observed up to $92 \%$ after $140 \mathrm{~min}$ of exposure to visible light.

The paper "Preparation and characterization of highly efficient and stable visible-light-responsive photocatalyst $\mathrm{AgBr} /$ $\mathrm{Ag}_{3} \mathrm{PO}_{4}$ " described preparation and photocatalytic performance of $\mathrm{AgBr} / \mathrm{Ag}_{3} \mathrm{PO}_{4}$ photocatalyst by a facile coprecipitation method. The activity of the photocatalyst was evaluated by the degradation of methyl orange (MO) and rhodamine $\mathrm{B}(\mathrm{RhB})$, indicating that the prepared $\mathrm{AgBr} / \mathrm{Ag}_{3} \mathrm{PO}_{4}$ exhibited excellent performance and much higher photocatalytic activity than the single one under visible light irradiation. The optimum mole ratio of $\mathrm{Br} / \mathrm{P}$ in $\mathrm{AgBr} / \mathrm{Ag}_{3} \mathrm{PO}_{4}$ samples is 0.3.

In "Preparation of bismuth oxide photocatalyst and its application in white-light LEDs," bismuth oxide photocatalysts were synthesized and coated on the front surface of phosphor-converted white-light-emitting diodes to produce a safe and environmentally benign lighting source.

In "Hydrothermal synthesis and characterization of $\mathrm{Bi}_{2} \mathrm{MoO}_{6}$ nanoplates and their photocatalytic activities," the $\mathrm{pH}$ effect of the precursor solutions on the phase, morphologies, and photocatalytic activity of $\mathrm{Bi}_{2} \mathrm{MoO}_{6}$ synthesized by a hydrothermal reaction at $180^{\circ} \mathrm{C}$ for $20 \mathrm{~h}$ was investigated. The photocatalytic activity of $\mathrm{Bi}_{2} \mathrm{MoO}_{6}$ nanoplates at the $\mathrm{pH} 6$ determined via the decomposition of rhodamine $\mathrm{B}(\mathrm{RhB})$ organic dye was the highest at $98.66 \%$ decolorization under Xe light irradiation.

In "Transport behavior of engineered nanosized photocatalytic materials in water," this review paper reports the transport of engineered photocatalytic nanoparticles (PCNPs) in water by addressing the important factors that determine the transport of PCNPs, such as particle size, $\mathrm{pH}$ value, ionic strength (IS), ionic valence, and organic matter. The potential risks of PCNPs are also mentioned due to easily entering the environment with the rapid increase in their manufacture and use.

The paper "Visible light photoelectrochemical properties of $\mathrm{N}$-doped $\mathrm{TiO}_{2}$ nanorod arrays from $\mathrm{TiN}$ " reported preparation of $\mathrm{N}$-doped $\mathrm{TiO}_{2}$ nanorod arrays (NRAs) by annealing the TiN nanorod arrays (NRAs), which were deposited by using oblique angle deposition (OAD) technique. All of the $\mathrm{N}$-doped $\mathrm{TiO}_{2}$ NRAs exhibit the enhanced photocurrent intensity under visible light as compared to pure $\mathrm{TiO}_{2}$ and TiN, and the sample annealed for 15 min shows the maximum photocurrent intensity due to the optimal $\mathrm{N}$ dopant concentration.

In "Photocatalytic characterization of $\mathrm{Fe}$ - and $\mathrm{Cu}$-doped $\mathrm{ZnO}$ nanorods synthesized by cohydrolysis," Fe- and Cu-doped $\mathrm{ZnO}$ nanorods are synthesized by employing a hydrolysis of $\mathrm{Zn}, \mathrm{Fe}$, and $\mathrm{Cu}$ metal nanopowders, which shows higher photocatalytic activity than pure $\mathrm{ZnO}$ in degradation of phenol in an aqueous solution.

\section{Acknowledgment}

We would like to express our sincere thanks to all the authors for submitting their interesting works to this special issue.

Jiaguo Yu Christos Trapalis Huogen $\mathrm{Yu}$ Wenhong Fan Hong Liu 

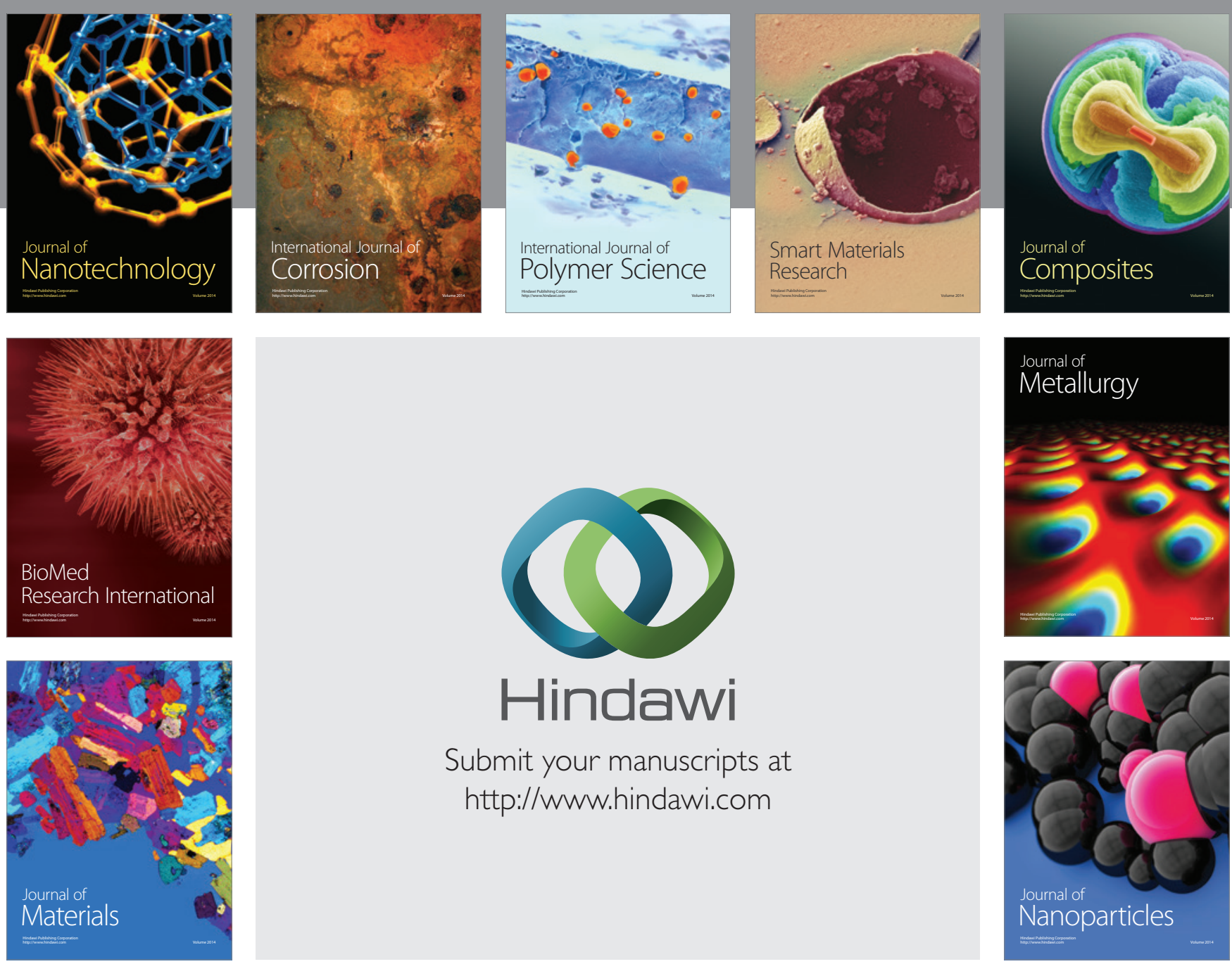

Submit your manuscripts at http://www.hindawi.com
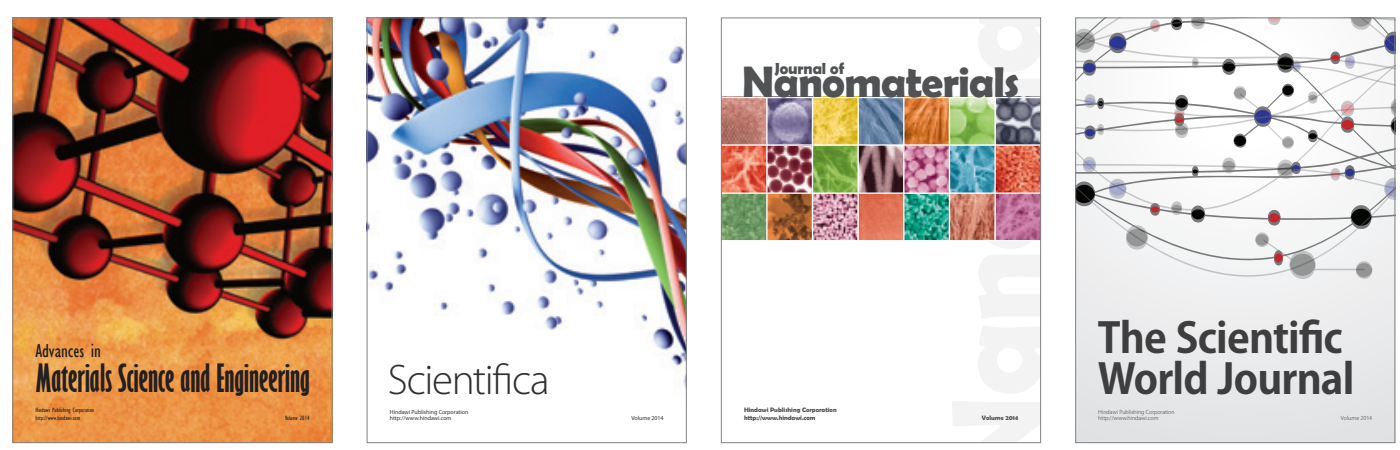

\section{The Scientific World Journal}
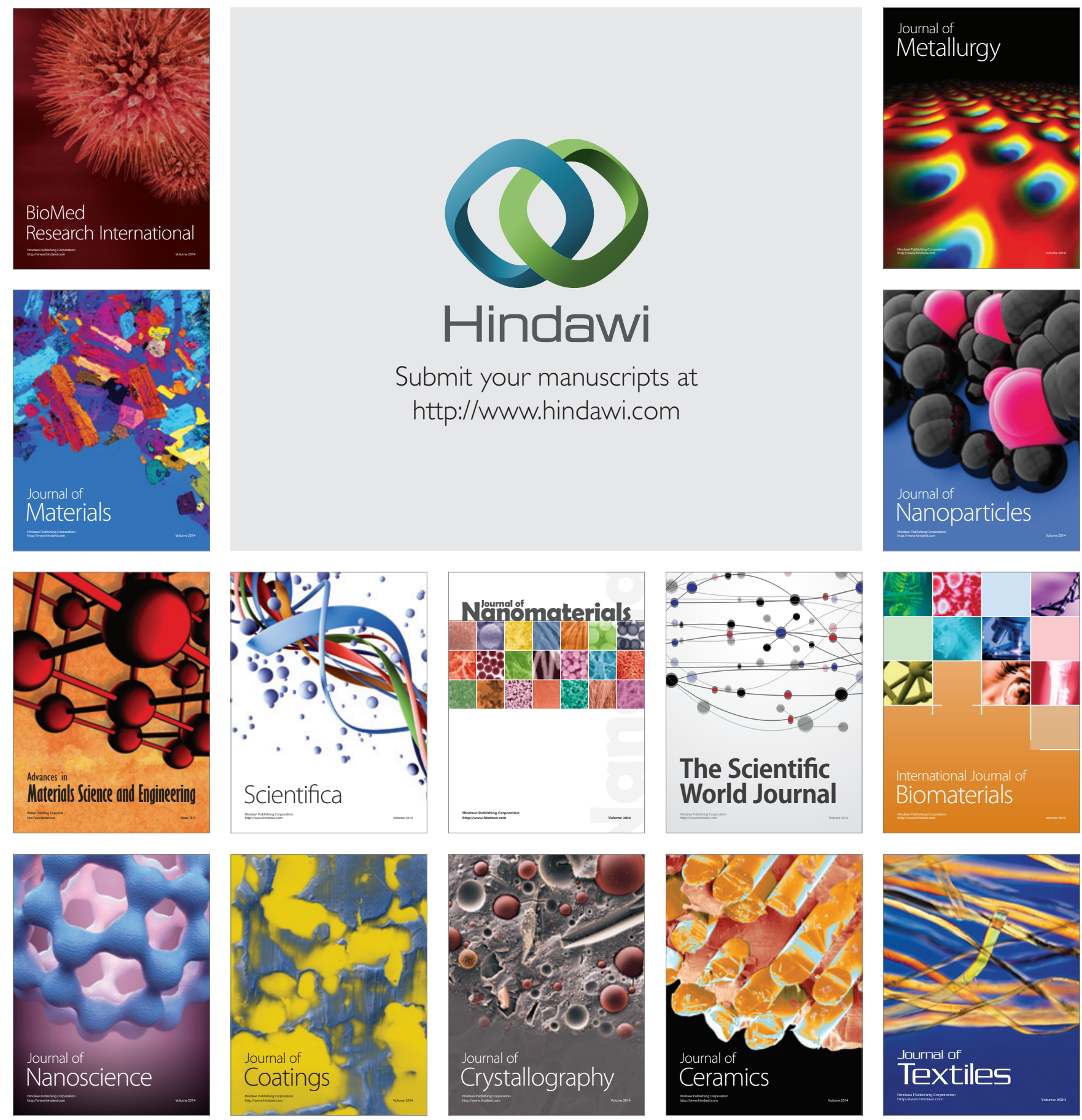